\title{
PROSPECCIÓN, PAISAJE Y EL “GRAN CUADRO” DE LA HISTORIA AGRARIA: UNA REVISIÓN CRÍTICA Y ALGUNAS PROPUESTAS
}

\section{ARCHAEOLOGICAL SURVEY, LANDSCAPE, AND “THE BIG PICTURE" OF AGRARIAN HISTORY: A CRITICAL REVIEW AND SOME PROPOSALS.}

\author{
Victorino Mayoral-Herrera ${ }^{1}$ y Luis Sevillano-Perea ${ }^{2}$ \\ 1. Instituto de Arqueología - Mérida. España. E-mail: vmayoral@iam.csic.es \\ 2. Instituto de Arqueología - Mérida.. España. E-mail: lsevillano@iam.csic.es
}

Presentado el: 15/11/2012 - Aceptado 02/08/2013

\begin{abstract}
Resumen
El propósito de este trabajo es proponer algunos puntos de reflexión acerca de la manera de concebir el estudio arqueológico del paisaje, así como sobre el papel que juega en este la prospección de superficie. Se llama la atención sobre la robustez de las propuestas teóricas de los años 80 y 90, y se reclama la necesidad de continuar articulando nuestra praxis siguiendo la pauta de programas de investigación coherentes y bien estructurados. De manera más amplia se plantea el potencial que tiene en esa dirección renovar una apuesta por una "arqueología agraria", reivindicando la valía de conceptos que encierran aún un vasto potencial de desarrollo en la investigación española. En concordancia con todo ello se señala la importancia de diseños metodológicos de prospección adecuados para afrontar el tratamiento de la compleja realidad de los paisajes agrarios. Se expone en este sentido una revisión de tendencias recientes así como de desafíos para el futuro, especialmente en lo referente a la documentación de la evidencia off-site. Finalmente, se plantean algunas propuestas acerca del sentido y utilidad de "espacios híbridos" de investigación, orientados a lograr una aproximación realmente diacrónica del estudio de los paisajes culturales.
\end{abstract}

Palabras claves: Arqueología del Paisaje; Paisajes agrarios ; Prospección superficial; Registro off-site

\begin{abstract}
The aim of this paper is to offer some thoughts about the way we conceive archaeological study of landscapes, and the role played by surface survey on it. We stress the robustness of theoretical proposals of the 80`s and 90's in Spain. We claim for the need of continuity in guiding our praxis by coherent and well structured research programmes. In a wider sense, we pose the need of renewing
\end{abstract}


a commitment with the proposals of an "agrarian archaeology". We claim for the value of theoretical concepts that still have a high potential for development in Spanish research. In this framework we stress the importance of methodological design of surface survey, in order to deal with the complex reality of agrarian landscapes. Some recent trends and challenges for the future are outlined, especially regarding the recording of the off-site finds. Finally, we suggest some proposals about the sense and utility of hybrid spaces of research oriented to a true diachronic approach to the study of cultural landscapes.

Keywords: Landscape Archaeology; Agrarian landscapes; Surface survey; Off-site record

\section{Antecedentes. Historia de un desarrollo (en parte) frustrado.}

Podría decirse que para la arqueología como disciplina científica, y particularmente en los estudios sobre el territorio, en la España de entre mediados de los años 80 y los 90 del siglo XX se vivieron tiempos de "grandes esperanzas". El relevo generacional de la Academia trajo consigo la llegada de una hornada de profesionales atentos a la profunda renovación teórica y metodológica que venía experimentando la disciplina desde más de una década antes, especialmente en el ámbito anglosajón, pero también de manera importante a través de corrientes de investigación surgidas en países como Francia e Italia (Martínez Navarrete 1997-1998: 330-331).

El fruto de este proceso dialéctico fue la progresiva maduración de propuestas comprensivas y robustas acerca del concepto de paisaje, bien partiendo de presupuestos teóricos de raigambre materialista: Juan Vicent para la Prehistoria Reciente desde el CSIC (Vicent 1991), Arturo Ruiz y Manuel Molinos para la Protohistoria (Ruíz Rodríguez 1988; Ruíz Rodríguez y Molinos 1979, 1984; Ruíz Rodríguez et al. 1988), Miquel Barceló para el mundo medieval (Barceló 1988)... o bien inspiradas por otras corrientes como el estructuralismo (Criado Boado 1993, 1999) o el procesualismo (Ruíz Zapatero y Burillo Mozota 1988). La dimensión territorial quedó así brillantemente articulada a través de esquemas que integraban de una manera coherente diversas escalas de resolución espacial, desde las unidades mínimas de habitación, producción y consumo, hasta las demarcaciones de carácter regional. Se trataba asimismo de planteamientos que tenían la vocación de ofrecer un marco explicativo global del comportamiento humano a través de su huella material. Las sucesivas reuniones científicas organizadas por el grupo de investigación del Colegio Universitario de Teruel, publicadas en la revista Arqueología Espacial, permanecerán como testimonio de esta etapa de eclosión.

Esta renovación de conceptos coincidió en el tiempo con la redefinición del modelo territorial español. La adopción del sistema autonómico trajo consigo la transferencia de competencias en materia de patrimonio, lo cual condujo a la puesta en marcha de ambiciosos proyectos de catalogación e inventario de zonas arqueológicas.

Ambas circunstancias confluyeron en la proliferación de estudios territoriales orientados a realizar síntesis de la evolución histórica de regiones amplias. Se produjo un crecimiento sustancial en el volumen y calidad del registro arqueológico relativo a estos problemas, completándose la información sobre amplios espacios vacíos. Al mismo tiempo, y para dar respuesta a estas demandas, estos trabajos fueron caldo de cultivo para fomentar la reflexión sobre los métodos de documentación empleada, adquiriendo la prospección superficial un papel protagonista. También en este sentido la arqueología española de esta etapa fue muy receptiva al pujante desarrollo que se estaba produciendo fuera de nuestras fronteras, y que ha conducido a la consolidación de la prospección como un recurso de primer orden en la investigación sobre el pasado. 
Pero como ya observó hace tiempo Ruiz Zapatero (2004), muchas de las expectativas creadas en esa etapa respecto al potencial de la investigación sobre el paisaje se han visto truncadas, o cuando menos han visto frenado su desarrollo. Desde el plano de la reflexión teórica, pensamos que uno de los factores de fondo que han influido en este sentido es la creciente crisis de los grandes paradigmas teóricos, o cuando menos el abandono de los mismos en tanto que dispositivos heurísticos como respaldo para el diseño de los programas de investigación.

En una dimensión más práctica, el mismo autor señalaba cómo, a diferencia de la tendencia mostrada en otros ámbitos de la región Mediterránea, los grandes proyectos regionales fundamentados en este tipo de trabajos no han tenido un crecimiento destacado. Aún hoy domina en nuestra profesión una actitud de escepticismo que tiende a situar a la prospección superficial en un estatus metodológico inferior. En buena medida este rechazo se fundamenta en la convicción de que los condicionantes respecto a la conservación y representatividad del registro material de superficie son demasiado fuertes como para poder obtener un conocimiento significativo sobre la estructura espacial de entidades arqueológicas.

Como consecuencia, la comunidad de investigadores consagrados al desarrollo metodológico de la prospección, o al menos a una aplicación consciente de procedimientos ya aceptados, sigue siendo minoritaria. La componente de experimentación que requeriría la contrastación de la validez de los sistemas de registro brilla prácticamente por su ausencia. Este carácter limitado fomenta además la multiplicación de iniciativas con poca interconexión, creando un efecto de "torre de Babel" que dificulta la posibilidad de comparar los resultados de los diferentes proyectos (algo que en todo caso no es exclusivo de nuestra investigación peninsular, tal y como plantean trabajos como el de Alcock y Cherry 2004).

Paralelamente, la realización de prospecciones superficiales se ha convertido en una parte sustancial de las intervenciones arqueológicas, en la medida en que constituye un requisito de cualquier estudio de impacto en una obra civil. Sin embargo, como valoraremos más adelante, existe un divorcio acentuado entre el desarrollo metodológico de la prospección y la praxis profesional. Los proyectos de excavación suelen requerir por parte de la administración una especificación de los métodos de registro y una homologación a procedimientos aceptados, como por ejemplo el uso del sistema Harris/Carandini (Harris 1991; Carandini 1997). En el caso de la inspección superficial en cambio, la unificación de la documentación se centra en la cumplimentación de fichas que inquieren sobre todo acerca de la tipología, cronología y estado de conservación de los hallazgos, pero que asumen la categoría de "yacimiento" como principal entidad del registro.

La señalada tendencia a la fragmentación y el eclecticismo teórico contrasta con la sofisticación tecnológica de muchos estudios territoriales, fruto en buena medida de la democratización en el acceso a las herramientas informáticas. Los Sistemas de Información Geográfica han sido definitivamente interiorizados como plataforma para la gestión y análisis del componente espacial de los datos arqueológicos (Conolly y Lake 2006; Grau 2006; Wheatley y Gillings 2002). En un sentido estrictamente funcional, estos medios han penetrado en nuestra práctica cotidiana. Sería por ejemplo irrelevante destacar aquí la disponibilidad generalizada de sistemas de posicionamiento que han desterrado del campo la cartografía en papel y (casi) erradicado los errores de localización. No obstante, un acceso universal a datos y software, que es positivo de por sí, entraña riesgos para una generación a veces tentada por el "síndrome de apretar el botón". La formación predominantemente 
humanística de los arqueólogos supone un hándicap para afrontar la comprensión de la matemática subyacente a los cada vez más amigables interfaces de los programas. Estos son capaces de hacer cada vez más cosas, lo cual conduce a que en no pocas ocasiones la herramienta dirige al usuario y no a la inversa (esta falsa neutralidad de los SIG ha sido agudamente denunciada por Gillings 2000).

Pensamos que otra tendencia actual respecto al uso de estas tecnologías consiste en su orientación hacia aspectos muy específicos del modelado de fenómenos del pasado. Frente a los viejos problemas de análisis espacial planteados por la escuela procesual (y que con estos nuevos soporte pueden ser abordados con extrema facilidad) los jóvenes practicantes de este tipo de aplicaciones se ven mucho más atraídos por la simulación numérica de aspectos más subjetivos del comportamiento de los grupos humanos, como su percepción del entorno mediante las relaciones de visibilidad o el movimiento a través del paisaje (una muestra de ello puede verse a través de Mayoral y Celestino 2011). Esto en sí mismo refleja una diversificación y un enriquecimiento en el espectro de facetas del comportamiento humano que son valoradas.

\section{La historia agraria como elemento articulador}

Dentro de este panorama rico a la vez que fragmentario y desigual, estimamos que la prospección arqueológica puede ofrecer su máximo potencial a partir de su inserción en programas de investigación coherentes y bien estructurados. No se trata de reivindicar la recuperación de un paradigma determinado. En cualquier caso es clara la necesidad de abordar el registro desde un modelo que tome nota de las insatisfacciones, pero con el que no nos perdamos en un laberinto de aspectos particulares o, peor aún, sigamos adelante repitiendo miméticamente una práctica arqueológica sin pensar para qué hacemos lo que hacemos.

Siguiendo en esa dirección, y retomando el discurso planteado por otros autores (Orejas 2006) querríamos buscar un vínculo entre viejos modelos y necesidades actuales a través de la perspectiva que aporta la Historia agraria. Definida como tal, dicha disciplina es en España casi con exclusividad dominio de especialistas en el mundo medieval, moderno y contemporáneo. No es este lugar para un análisis detenido del papel de la dimensión material del mundo agrario en estos trabajos. Eso sí, se ha de señalar cómo esta situación contrasta con la ofrecida por países como Francia, Inglaterra o los Países Bajos, en los que los estudios de cultura material de raigambre braudeliana, junto con otras tradiciones de análisis histórico del paisaje, nos dejan un impresionante legado científico (véase por ejemplo las obras de Barker 1995 o Cherry 1991).

Ya hemos mencionado cómo desde la Arqueología han sido formuladas propuestas de gran robustez para el estudio del mundo agrario. Algunas estuvieron claramente inspiradas por la Escuela de Annales, en un afán de integrar la pluralidad de disciplinas relacionadas con el conocimiento de lo agrario (Guilaine 1991). Ese llamamiento tuvo tempranos ecos en la Península Ibérica. Desde la prehistoria, el concepto de paisaje agrario fue ambiciosamente abordado por autores como Vicent (1991), que propusieron una aproximación específicamente arqueológica a este problema, tomando como referencia esquemas conceptuales de la geografía humana. Se planteaba así una "arqueo-geografía" del paisaje humano del pasado, atenta a la idiosincrasia del registro material, y siempre contextualizada en el estudio de formaciones sociales y contextos históricos específicos. 
Una línea de indagación con parámetros similares puede rastrearse a través de algunos sectores de la arqueología medieval española. Emanando de la citada tradición de estudios de geografía rural francesa, es de cita obligada la labor de autores centrados en el mundo islámico como Patrice Cressier (1983), André Bazzana (1983) o Pierre Guichard. Desde un paradigma teórico diferente, ya durante los años 80 Barceló (1988) llama la atención sobre la necesidad de desplazar el objeto de atención de la arqueología, desde los espacios y ámbitos en los que el poder y la desigualdad social es representada, hacia aquellos en los que estas relaciones se ejercen de facto. Una arqueología que desplace el foco de las residencias de la elite o los centros de culto hacia los campos de cultivo y otros espacios de producción. Esta orientación fructifica en un amplio conjunto de estudios de filiación materialista centrada en los paisajes irrigados islámicos.

Esta línea de trabajo va a confluir con experiencias surgidas de las grandes intervenciones preventivas en lugares como Madrid, en las que la excavación en área coloca a los arqueólogos frente a una enorme diversidad de indicios de ocupación más allá de los "sitios" (Kirchner 2010). De manera análoga a como ha sucedido en otros países europeos, de la identificación formal de los campos y sus múltiples indicios asociados, se pasó a la excavación de los mismos y al establecimiento de vastas estratigrafías horizontales (véase por ejemplo el tipo de trabajos planteados en Miller y Gleason 1998). Otra de las consecuencias de estos estudios fue la contextualización de conjuntos de materiales de baja densidad y no asociados a estructuras de habitación, evidencia que nos lleva al registro superficial off-site del que hablaremos en extensión más adelante.

Por un camino similar, las grandes excavaciones provocadas por la expansión urbana de Jaén condujeron a la documentación de sistemas de campos, estructuras para la gestión del agua y pequeñas construcciones rurales, con una cronología que se extendía desde la prehistoria reciente hasta época moderna. En este caso los resultados encuentran su marco explicativo en las propuestas de análisis histórico del grupo de investigación del Centro Andaluz de Arqueología Ibérica, a las que ya hemos hecho alusión (Ruiz Rodríguez 2007).

Siguiendo por este recorrido de una Arqueología de los campos cultivados, es preciso además hacer referencia a trabajos de documentación de este tipo de estructuras en el Noroeste peninsular, como es el caso de las registradas por Parcero (2006) para la Edad del Hierro, así como a los sistemas de aterrazamiento estudiados por Ruiz del Árbol (2005, 2006) en el marco de la investigación sobre los paisajes agrarios y mineros romanos en las actuales provincias de León y Zamora.

Si fijamos la mirada sobre el ámbito del suroeste peninsular, nos encontramos con el grupo de investigación de la Universidad de Extremadura, que desde inicios de este siglo ha propugnado el desarrollo de una línea de trabajo centrada en la "arqueología rural". En buena medida esta labor está inspirada en las propuestas teóricas y de estructuración metodológica defendidas por Arturo Ruiz desde Jaén. Su llamada de atención sobre la necesidad de abordar el estudio de "los otros" sujetos del proceso histórico (Rodríguez Díaz 2009: 14) sigue siendo pertinente en una disciplina que a menudo se ve fatalmente atraída por el discurso elaborado desde las clases dirigentes. No es menos estimable su apuesta por otra línea de investigación que tiene un desarrollo creciente como es la "arqueología de la población" (Burillo Mozota 2010). En ella vemos un buen ejemplo de la utilización de métodos de experimentación de raigambre procesual como herramientas heurísticas para abordar preguntas esenciales en el estudio de los paisajes agrarios. Las estimaciones 
demográficas son necesarias para ponderar el impacto y la sostenibilidad de los modelos de explotación o la escala de las relaciones de producción, y la prospección superficial juega un papel muy significativo en la elaboración de estas estimaciones.

\section{La prospección superficial en la encrucijada}

Si lo que se pretende es que la prospección arqueológica juegue un papel relevante en la contrastación de modelos explicativos complejos del comportamiento humano en el paisaje, una premisa esencial es que adaptemos su corpus metodológico en función de las demandas que estos nos plantean.

Como ya se ha apuntado, el incremento de este tipo de trabajos durante la década de los ochenta y noventa del siglo XX supuso un salto cualitativo de notable importancia en cuanto al volumen y naturaleza de la documentación arqueológica superficial. Pese a las tendencias inmovilistas ya señaladas, las inquietudes renovadoras nunca estuvieron del todo ausentes en los proyectos de prospección, y las líneas maestras de ese proceso de renovación tienen buenos precedentes. Es de obligada referencia a la hora de señalar experiencias pioneras el estudio territorial del Ager Tarraconensis (Carreté et al. 1995), que supuso una plasmación práctica del potencial de la prospección estadística frente al tradicional predominio de enfoques de carácter selectivo.

En la misma dirección hay que destacar desde inicios de los 90 los trabajos desarrollados en el Valle del Tajuña (Almagro y Benito 1993). En ellos además este enfoque cuantitativo aspira a controlar los diversos factores que introducen sesgos en la representatividad del registro superficial, algo en lo que insistiremos más adelante. Podemos por otro lado conectar estas experiencias con el trabajo llevado a cabo en otros contextos históricos y geográficos (Martín Bravo 1994, 1996; Quesada y Vaquerizo 1990). Estos casos ponen de manifiesto la preocupación por establecer criterios de control estadístico (mediante muestreos de tipo aleatorio) que permitan ponderar el sesgo que introduce en nuestras lecturas territoriales una exploración dominada por patrones de asentamiento previamente conocidos

Con el tiempo, esta aplicación de técnicas de muestreo se ha generalizado en las inspecciones visuales de superficie. Sin embargo hay que señalar que, aunque en un plano teórico los efectos de la utilización de diferentes diseños son reconocidos (véanse propuestas de manual en trabajos como los de Fernández Martínez 1985 o Ruíz Zapatero y Fernández Martínez 1993), es aún limitado el control que tenemos sobre las implicaciones de estos principios sobre el terreno. La única vía para validar hipótesis al respecto es la experimentación. Esto trae consigo la necesidad de re-prospectar, tarea no siempre viable dadas las limitaciones materiales habituales en nuestra actividad de campo.

Por tanto en definitiva, no podemos obviar una reflexión sobre la problemática que lleva implícita la prospección estadística, la cual no es por sí misma una estrategia mejor (véase una inteligente contraposición entre el uso de estos métodos y los de carácter selectivo en Banning 2002). Como siempre la clave está en aceptar y acotar el peso de los condicionantes en el documento arqueológico que construimos a partir de una determinada estrategia de prospección. 


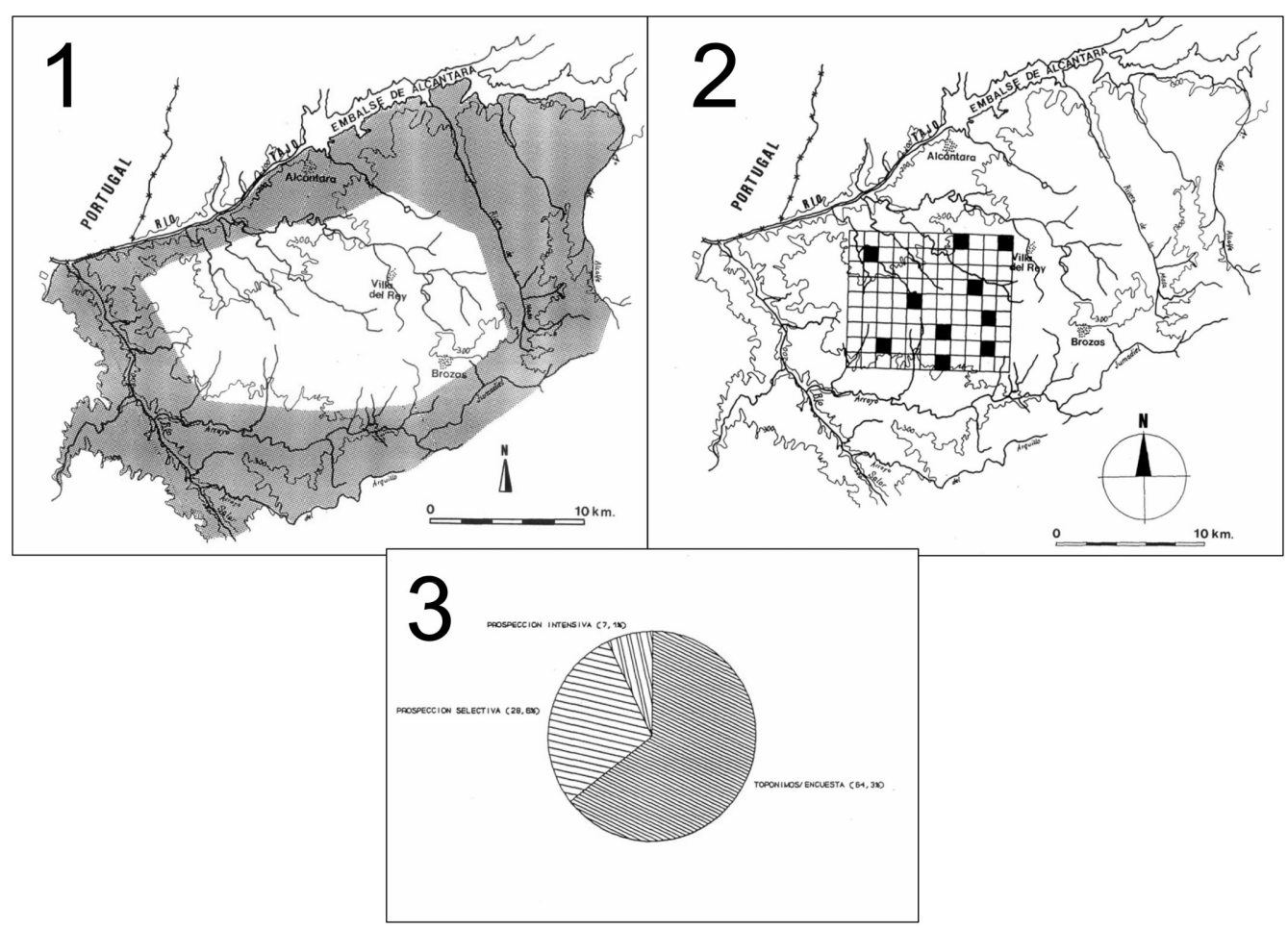

Figura 1. Ejemplo de prospección intensiva a escala regional basada en técnicas de muestreo. Tomado del trabajo de Martín Bravo en la zona de Alcántara (Cáceres). Número 1: área inspeccionada mediante prospección guiada. Número 2: distribución de la prospección aleatoria. Número 3: porcentajes de los espacios prospectados mediante las diferentes técnicas. (Martín Bravo 1994: Figuras 3, 4 y 5).

Estrechamente ligado con el diseño muestral de las prospecciones está el problema de la relación entre los conjuntos superficiales y el conjunto total de los depósitos arqueológicos. En este punto es interesante recordar los experimentos llevados a cabo por Díez Martín para comprobar la proporción de artefactos que se encuentran en superficie y en la totalidad del paquete de arada (Díez Martín 1999) que ofrecen una réplica peninsular a experiencias previas tanto en el ámbito mediterráneo (Ammerman 1985) como en EEUU (Dunnel y Simek 1995; Shott 1995). Dentro de este tipo de estudios, la formación del registro arqueológico ha ido captando un creciente interés (Esteban et al. 1996), así como la relación de los elementos de superficie con los posibles restos que se encuentren en el subsuelo (Lorrio y Fernández 1986) y con los procesos postdeposicionales tanto antrópicos como originados por los agentes naturales (Burillo Mozota y Peña Monné 1984; Burillo Mozota 1996; Díez Martín 2009).

Junto con esta apuesta por la aplicación de la estadística, otra de las tendencias en las que el desarrollo peninsular acusa la influencia externa es en la progresiva reducción de los ámbitos de estudio. Ello es en parte reflejo de las críticas de las corrientes postprocesuales hacia la validez de leyes generales de aplicación macroespacial o regional. Asimismo la limitación de los espacios de prospección es fruto de una gradual comprensión de los procesos acontecidos en el paisaje a menor escala (Chapa et al. 2003; Burillo Mozota 2004, Mayoral et al. 2009), cuando no de la toma de conciencia de que ámbitos muy reducidos como el propio sitio arqueológico pueden ser analizados como "paisajes en miniatura" (Gutiérrez 1998, 2010; Hurtado 2000; Chapa et al. 2004). 


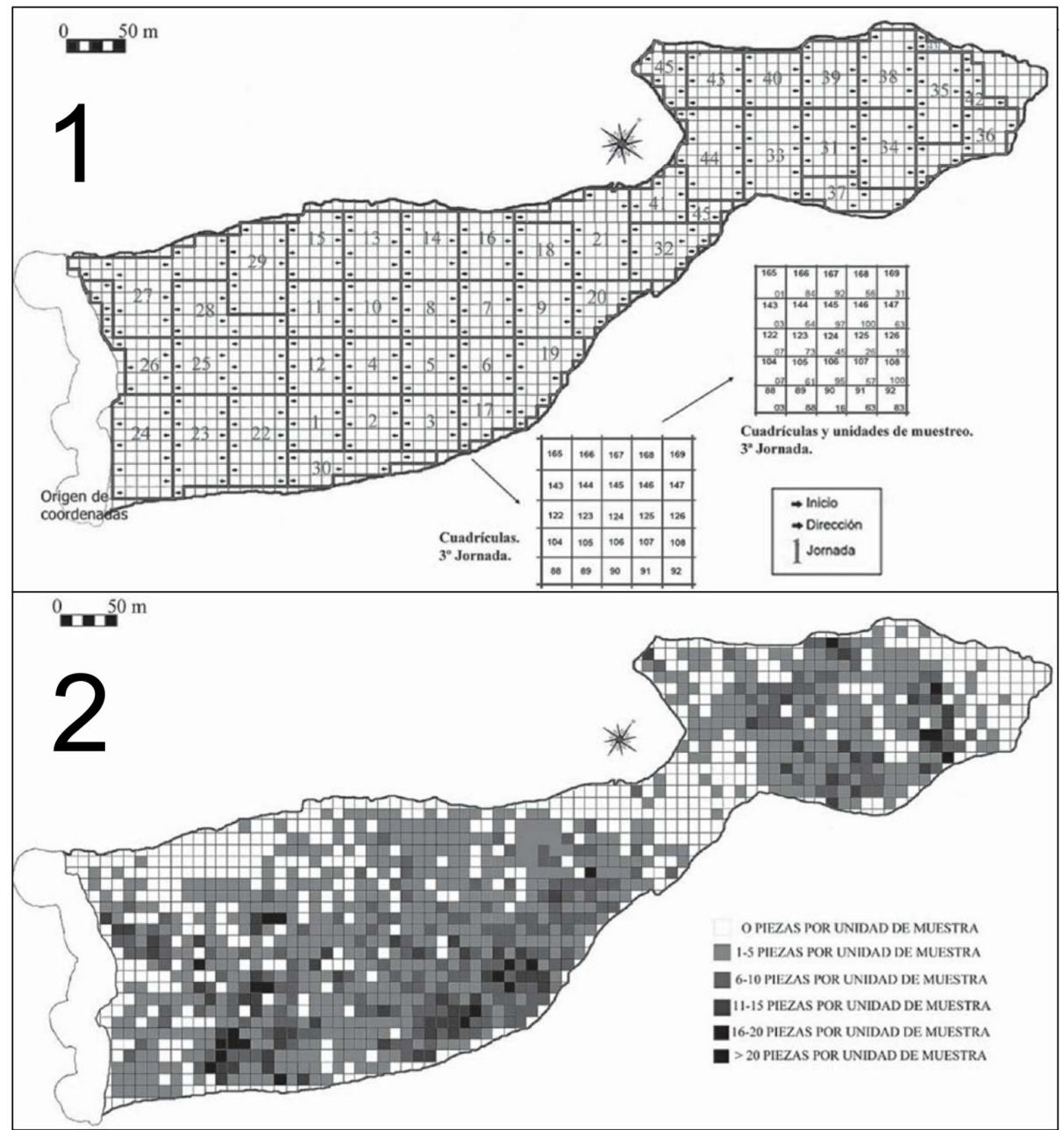

Figura 2. Ejemplo de prospección estadística a escala de sitio. El oppidum de Giribaile (Jaén). Número 1: organización de estratos cuadrículas y unidades de muestra. Número 2: distribución de la abundancia de materiales por unidades de muestra (Gutiérrez Soler 2010: Figuras 4 y 8).

Además de esta serie de condicionantes, otro importante ámbito de desarrollo metodológico se refiere a la observación y control de diversos factores que afectan a la fiabilidad documento arqueológico de superficie. Estos incluyen en primer lugar aspectos como el efecto sobre los resultados del trabajo de campo de la visibilidad superficial o la cantidad de luz que incide sobre la superficie. Aunque el corpus bibliográfico existente sobre este asunto no es muy extenso, lo escrito aporta sólidos argumentos sobre la variabilidad de estos factores, así como acerca de la necesidad de tratar de comprender su comportamiento para inferir su posible impacto en el documento arqueológico de superficie. Todo ello ha conducido a la elaboración de diversos factores de corrección que, aunque han sido en ocasiones muy cuestionados, son de aplicación común en diversos proyectos de prospección del ámbito mediterráneo (Bintliff et al. 1999; Fanning y Holdaway 2004; Shennan 1985; Wandsnider y Camilli 1992). 
De una manera más o menos intuitiva estas preocupaciones han quedado expresadas en las experiencias de prospección españolas. Así se ha prodigado el diseño de fichas de prospección en las que se prestaba una atención especial al registro de las condiciones de la superficie del terreno y/o atmosféricas. Sin embargo la explotación efectiva de esta información en el proceso de interpretación ha sido muy desigual, de manera que esta toma de conciencia no ha despertado gran interés a la hora de diseñar procedimientos formales de análisis. Pueden señalarse en todo caso algunas experiencias de contrastación estadística del peso de las variables relacionadas con la textura y el uso del suelo en la frecuencia de hallazgos, por ejemplo en el caso de las prospecciones del Guadiana Menor, en Jaén (Chapa et al. 2003).

Otro factor condicionante de nuestro registro superficial es la variable experiencia y percepción de los prospectores. De nuevo las referencias externas son significativas, aunque podemos no obstante encontrar algunos ejemplos peninsulares, especialmente durante la década de los noventa del siglo XX. Así por ejemplo el trabajo de San Miguel (1992) analiza la relación entre la frecuencia y cronología de los hallazgos, y otros factores como la experiencia de los miembros del equipo de prospección, la hora del hallazgo, las áreas topográficoecológicas etc. Los ya citados trabajos del Valle del Tajuña son otro interesante ejemplo de la preocupación por ponderar estas variables. Los datos de campo fueron sometidos a un estricto control para ver si cumplían unos determinados parámetros de calidad (Martín Bravo et al. 1996; Benito 2004).

\section{El artefacto y el sitio. Una discusión no resuelta.}

Como hemos visto hasta aquí, la paulatina sofisticación metodológica de los trabajos de prospección en la arqueología española ha dado frutos desiguales pero prometedores. Sin embargo, a nuestro modo de ver, existen determinados aspectos en los cuales el desarrollo de la disciplina en nuestro entorno se encuentra en un espacio de frontera. Ese carácter liminal viene definido por una discusión, que no es nueva en otras tradiciones de pensamiento arqueológico, en torno a la adopción de una unidad mínima de registro como parte esencial de las reglas heurísticas para enfrentarnos a la realidad material.

Dicha dicotomía tiene importantes implicaciones en cuanto a nuestra manera de concebir el comportamiento de los grupos humanos, así como en lo referente a la posibilidad de recuperar esa dimensión sistémica a partir de un registro complejo y dinámico como es el de la superficie. Ya hemos valorado detenidamente este aspecto al discutir sobre modelos explicativos para abordar el estudio de los paisajes agrarios. Lo que resulta crítico es analizar cómo esta diferencia de planteamientos se traduce en última instancia en la formulación de diferentes objetivos para las prospecciones superficiales.

En este sentido es claro cómo durante mucho tiempo la meta esencial y no cuestionada de la prospección ha sido la detección y documentación de "sitios". Ello no ha sido óbice para manifestar el desajuste entre dicha categoría y algunos tipos de evidencia que terminan por ser definidos como "hallazgos aislados". Traspasar el límite de la definición de los sitios como entidades espacialmente discretas nos coloca frente a un registro material que se distribuye de manera continua a través del paisaje. 


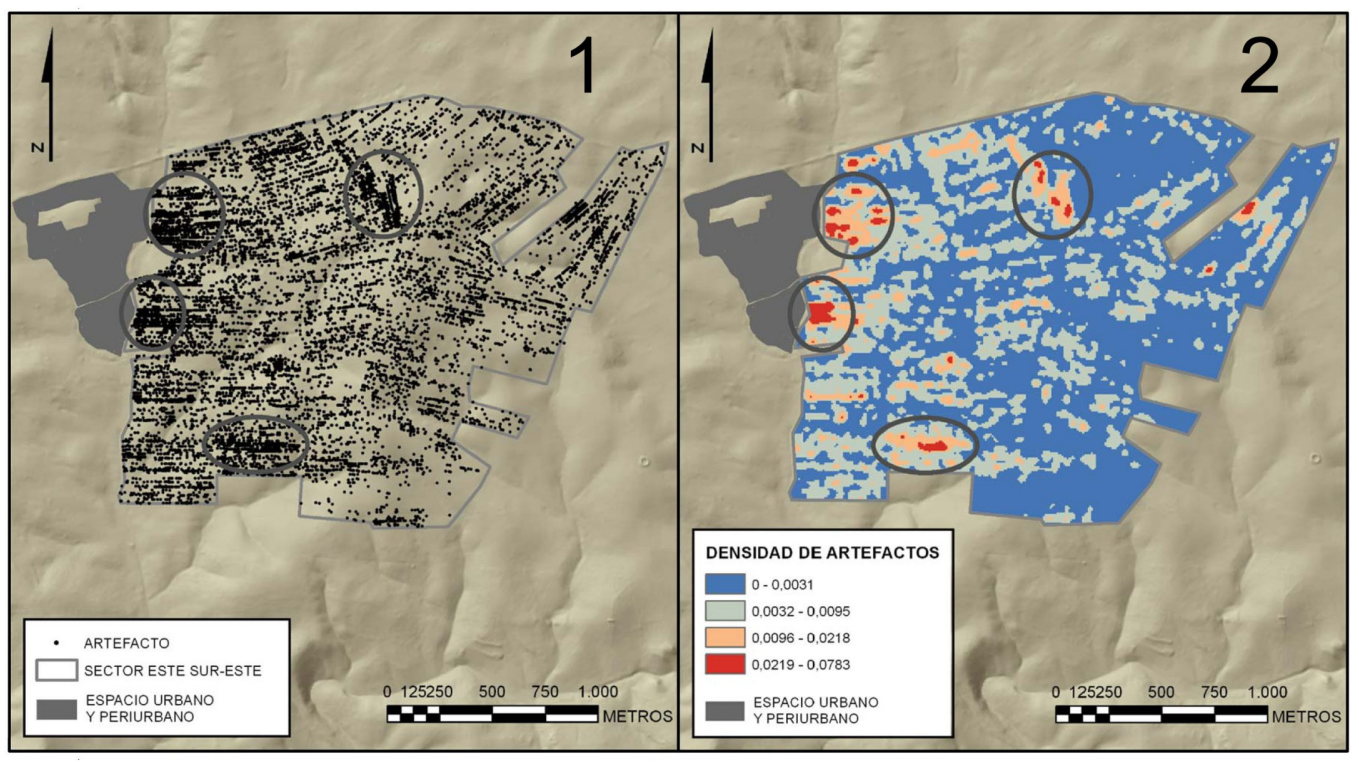

Figura 3. Una imagen ilustrativa de la realidad aparente que ofrece el registro off-site. Prospección intensiva en el entorno de la ciudad romana de Contributa Iulia (Medina de las Torres, Badajoz). En A se representa la elevada densidad de material superficial (cada punto representa un fragmento con una intensidad de 10 metros entre prospectores). Sin embargo en B se aprecia cómo sólo las áreas marcadas corresponden con entidades asimilables a la categoría de "sitio".

El principal potencial que desde nuestro punto de vista posee este segundo planteamiento es que permite hacer una clara diferenciación del documento arqueológico y la información que generamos. Los resultados del sistema de prospección que tienen al sitio como unidad mínima de registro llevan implícita una interpretación por parte del equipo de prospección. En campo se decide qué elementos forman parte de las áreas de interés y por tanto todos los datos que se registran están limitados por tal concepto, quedando pobremente representadas o directamente ausentes todas aquellas distribuciones de entidades arqueológicas que no puedan ser integradas dentro del término sitio.

Sin embargo, las estrategias de prospección basadas en el artefacto como unidad mínima de registro generan una documentación que debe ser interpretada a posteriori, y no durante la construcción del documento arqueológico. Como resultado, un mapa con un número de artefactos por metro cuadrado representará las variaciones en las distribuciones de artefactos. Definir la naturaleza de dichas distribuciones y sus densidades sería el siguiente paso, pero ya con carácter independiente a la toma de los datos. Con ello no estamos defendiendo una supuesta "mayor objetividad" de este sistema de documentación, que igualmente está condicionado por la concepción del registro arqueológico de superficie que mantenemos.

Las prospecciones non-site surgen como respuesta a dicha realidad material constatada: a veces los artefactos que se reparten sobre la superficie no forman grupos coherentes desde la visión tradicional y tampoco se pueden identificar como hallazgos aislados, pues presentan un determinado patrón de comportamiento. 
Las estrategias de prospección no centradas en el sitio arqueológico tuvieron una primera aplicación en EEUU y Europa. Sería en Norteamérica a finales de la década de 1970 cuando se puso en práctica la estrategia de prospección siteless (Dunnell y Dancey 1983). En este caso, el objetivo de los proyectos era analizar desde una perspectiva regional las culturas precoloniales. Sus contextos arqueológicos superficiales presentan distribuciones poco uniformes (tanto espacial como cronológicamente) de restos materiales consecuencia de actividad humana no sedentaria. Por ello las estrategias de prospección que tenían en el sitio o yacimiento arqueológico su unidad mínima de registro no concordaban con el tipo de conjuntos materiales que eran objeto de estudio.

En otras regiones como el Creciente Fértil (Wilkinson 2000), pero sobre todo en la Europa Mediterránea se ha desarrollado la estrategia de prospección off-site. En todas estas áreas se habían llevado a cabo previamente prospecciones superficiales centradas en la identificación de yacimientos arqueológicos, pero a partir de la década de 1980 se constató una realidad arqueológica que no podía ser correctamente documentada con las estrategias de prospección tradicionales. No sólo se identifican las grandes concentraciones de material que pueden identificarse fácilmente con sitios, término que se reconoce como válido para definir ciertos contextos arqueológicos, sino que registran distribuciones menos densas y más irregulares de elementos arqueológicos que igualmente evidencian actividades humanas en dicho entorno. Es por ello que se adoptó igualmente el artefacto como unidad mínima de registro para documentar los cambios espaciales en la distribución de los materiales (Bintliff y Snodgrass 1988; Wilkinson 1992).

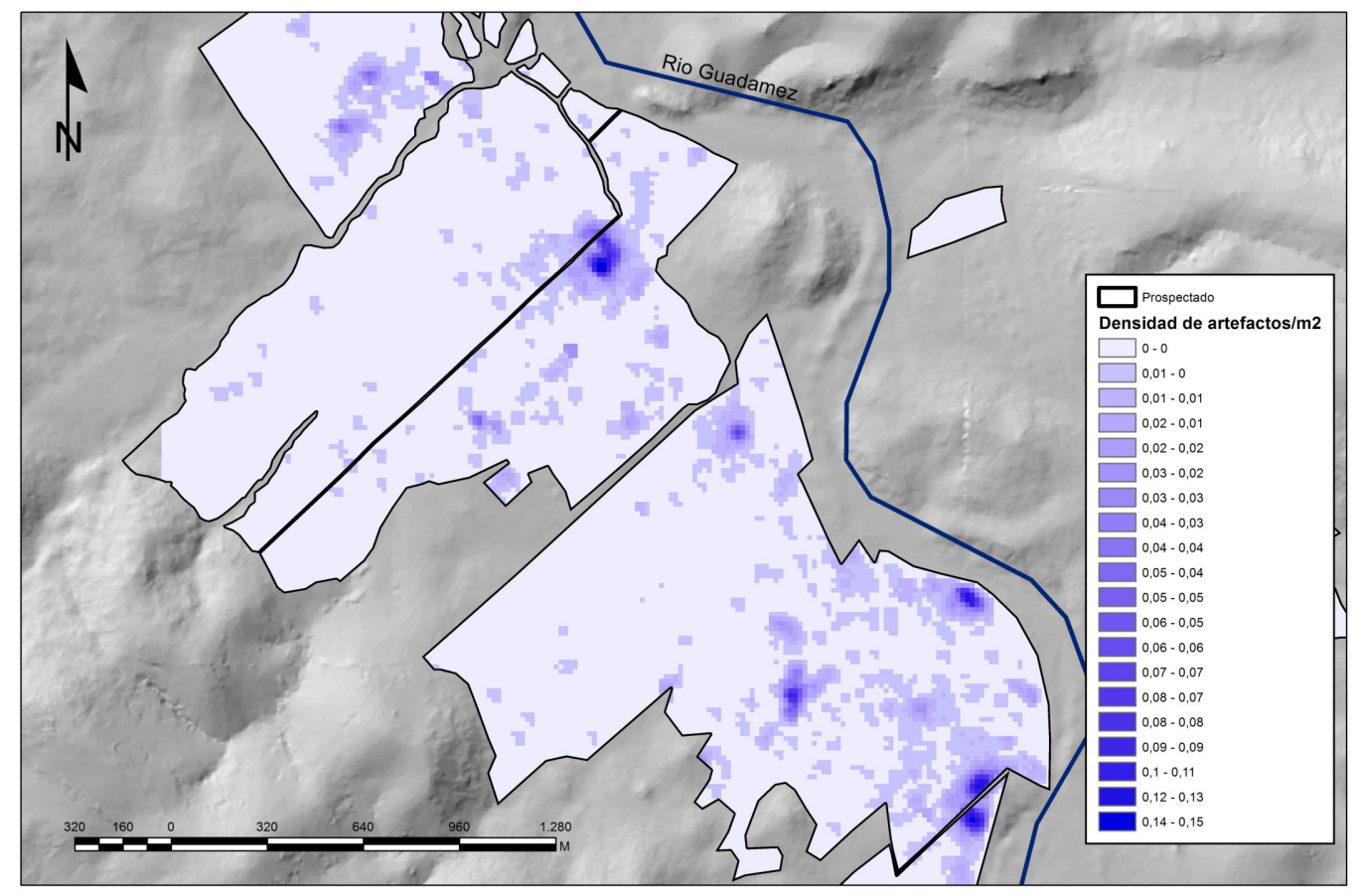

Figura 4. Asentamiento rural de época romana detectado durante las prospecciones en el Valle del Guadámez (Badajoz). El decaimiento progresivo de la densidad de hallazgos define con claridad el carácter difuso de las fronteras entre las zonas de actividad concentrada y el resto del paisaje. 
Por ello, la dificultad para definir y correlacionar los diferentes elementos que conforman el registro material de superficie ha dado lugar a la creación de diferentes términos que se han abierto camino para caracterizar la huella de procesos concretos en el paisaje. Así conceptos como espacios con anomalías culturales (Localized cultural anomalies: LOCA), lugares de interés especial (Places of special interest: POSI) o unidades topográficas, de uso tan extendido entre los estudios de arqueología del paisaje italianos (véase por ejemplo el uso de este concepto en Pasquinucci y Menchelli 2012), se unen a los de lugares de actividad concentrada o actividad dispersa con el objetivo de analizar la cambiante distribución de restos materiales en el suelo.

Si pensamos ahora en nuestro entorno peninsular, pueden citarse determinadas experiencias que han tenido un peso de enorme importancia en la expansión de las estrategias de prospección que tienen en el artefacto la unidad mínima de registro. Es así en el caso de los trabajos ya citados llevados a cabo en el Ager Tarraconensis, como en el entorno de Peñaflor, Córdoba (Keay et al.1989; Keay et al. 2001), que como ya dijimos han ejercido notable influencia en el diseño de estrategias de prospección posteriores especialmente en dichos ámbitos geográficos.

Es así como desde finales de la década de los noventa del siglo XX que se ha multiplicado el número de estudios que tienen en el ítem la unidad mínima de registro (Burillo Mozota et al. 2004: 170-171; García Sánchez 2012). Sin embargo, se ha prestado poca atención (y en esto no somos una excepción) al análisis de los datos que no forman conjuntos identificables como sitio arqueológico.

Esto supone movernos desde la constatación de un patrón espacial obtenido gracias al ajuste de nuestra metodología, hacia la búsqueda de una explicación en términos sistémicos, es decir, hacia la identificación de comportamientos en el marco de un paisaje agrario. Se reconoce la existencia de ciertas prácticas que dan lugar a estas distribuciones de materiales menos densas, pero el esfuerzo se centra en delimitar y analizar los cambios en la distribución cronológica y funcional de los artefactos dentro de los lugares que presentan una mayor cantidad de artefactos como resultado de la práctica de actividades concentradas. A este respecto el panorama hispánico contrasta con el proceloso debate desarrollado en otros ámbitos en torno a la denominada "hipótesis del abonado" (Wilkinson 1982, 1989; Alcock et al. 1994; Given 2004; Bintliff y Snodgrass 1988). Una propuesta en esta dirección quedó planteada para la campiña giennense (Mayoral et al. 2006, 2011). En dicho contexto el análisis de una extensa "alfombra" de material off-site pudo ser caracterizada, estableciéndose relaciones entre su presencia y prácticas agrarias intensivas entre finales del período ibérico y los inicios de la presencia romana. Siguiendo esta línea de trabajo nos hemos enfrentado más recientemente al estudio de los paisajes del suroeste peninsular (Mayoral et al. 2011), en los que podemos constatar complejas y densas distribuciones de material que cabría explicar en términos similares.

\section{Las políticas (no-)preventivas del registro arqueológico "fuera de sitio"}

Consideramos interesante reflexionar sobre la importancia que ha tenido el concepto de yacimiento (y el uso genérico de "sitio" como su paralelo para el registro arqueológico superficial) para la creación en un corpus legal del patrimonio histórico y arqueológico en España. Dicha normativa se adecúa a una idea de registro arqueológico que obvia buena parte de las entidades arqueológicas superficiales y, por otro lado, condiciona la documentación resultante de las prospecciones superficiales. 
Este proceso jurídico, nacido con idea de registrar, proteger y difundir posibles yacimientos arqueológicos ante el importante desarrollo inmobiliario y constructivo que ha experimentado el estado español en los últimos decenios, se inició durante los primeros años de la última década del siglo XX. Su inicio se encuentra en la Ley 16/1985 de 25 de Junio de Patrimonio Histórico Español y ha sido complementado durante la década de los noventa del siglo XX con las normativas que fueron aprobando las diferentes autonomías, siendo éstas renovadas o sustituidas posteriormente.

Para ese momento, el planteamiento metodológico de casi la totalidad de los proyectos territoriales que incluían prospección superficial en España (así como en buena parte del ámbito mediterráneo) entendía como objetivo primordial de esta etapa de la investigación la localización, delimitación y definición crono-funcional de concentraciones de artefactos. Dichas concentraciones se interpretaban como restos superficiales de yacimientos arqueológicos con estructuras en el subsuelo o completamente destruidos por los procesos postdeposicionales. Por lo tanto, la reglamentación referente a los estudios territoriales y a la prospección superficial particularmente se centra en el registro de las características de tales distribuciones de artefactos, cuyo resultado queda reflejado en las diferentes Cartas Arqueológicas. Un ejemplo notorio de la relación entre esta primera generación de prospecciones sistemáticas en España y la normativa legal desarrollada para el documentar y proteger al registro arqueológico superficial es la ficha diseñada por el equipo de la escuela universitaria de Teruel para la Carta Arqueológica de Aragón (Burillo Mozota et al. 1993).

Igualmente es interesante recordar el esfuerzo dedicado por algunas administraciones autonómicas a realizar mapas de análisis del potencial arqueológico. A modo de ejemplo destacado podemos citar la labor llevada a cabo desde el Instituto Andaluz de Patrimonio Histórico, donde se han sucedido varios proyectos desde el Sistema de Información del Patrimonio Histórico de Andalucía (Ladrón de Guevara y Muñoz 2007) hasta otros más recientes como MAPA, es decir, Modelo Andaluz de Predicción Arqueológica (Fernández Cacho y Rodrigo Cámara 2009). Este último fue elaborado a partir de la información previa de la localización de las entidades arqueológicas en conjunción con variables medioambientales, tratando de "predecir la probabilidad de presencia de yacimientos en áreas no estudiadas" (Díaz Iglesias et al. 2011: 5). Este instrumento pretende ser actualizado progresivamente incluyendo nuevos datos que se vayan generando a través de la aplicación PRONOS o Sistema de Cartografía Arqueológica Predictiva (Díaz Iglesias et al. 2011).

No obstante, como se ha visto anteriormente, la implementación de trabajos de prospección superficial con mayor intensidad ha puesto en evidencia la existencia de material arqueológico que no encaja dentro de la categoría de sitio/yacimiento. Y es palpable que las normativas regionales sobre patrimonio arqueológico no fueron redactadas para incluir figuras que protejan los artefactos de superficie "siteless". En cualquier caso, existen conceptos como el de zona arqueológica, donde la laxitud de su definición permitiría incluir el registro arqueológico fuera de sitio. La figura de zona arqueológica, que posee una definición muy similar en la mayoría de legislaciones regionales, se establece como "lugar o paraje natural en donde existan bienes muebles o inmuebles o restos de la intervención humana, susceptibles de ser estudiados con metodología arqueológica, tanto si se encuentra en la superficie como si se encuentran en el subsuelo, bajo las aguas o en construcciones emergentes" (Artículo 9 de Ley 10/1998, de 9 julio. Ley del Patrimonio Histórico de la Comunidad de Madrid). 
Sin embargo, este concepto, que se planteó especialmente para proteger potenciales áreas arqueológicas ante futuras alteraciones del terreno, no fue establecido teniendo en cuenta las características de las distribuciones arqueológicas que son resultado de actividades dispersas.

Como ya vimos, el reflejo material de las prácticas agrarias, así como otros agregados que resultan en conjuntos poco homogéneos y de bajas densidades, necesitan de determinadas estrategias de reconocimiento superficial para su documentación. A pesar de que este tipo de registro arqueológico de superficie puede verse incluido dentro de las figuras de protección del patrimonio arqueológico existentes en España, queda por lo general excluido de la catalogación que realizan las administraciones públicas de conjuntos arqueológicos y, por tanto, fuera de cualquier protocolo de protección que debería incluir como mínimo su correcta documentación ante cualquier episodio de alteración de la superficie.

Para ello, además de la necesidad de llevar a cabo actividades de registro del material siteless, sería de gran ayuda la implementación de modelos predictivos, puesto que para casos como el resultado del laboreo de parcelas agrícolas por un tiempo específico, la misma materialidad del suelo va a determinar las prácticas agrarias que se hayan podido repetir eficientemente en un entorno concreto. Por lo tanto, y debido a que las herramientas preventivas necesarias existen (tanto para analizar y determinar las potenciales áreas de interés, como para documentar dichas distribuciones), una mínima actuación debería ser exigida con anterioridad a una modificación significativa del registro arqueológico superficial.

Esta necesidad se hace crítica por cuanto son cada vez más los espacios agrarios en los que la introducción de nuevas prácticas de explotación está produciendo un fuerte impacto en la conservación de los depósitos arqueológicos. Un caso elocuente es el de los paisajes aluviales con una agricultura intensiva, como ocurre en la vega del Guadiana en torno al sitio histórico de Medellín (Badajoz) que hemos tenido la posibilidad de analizar en detalle (Sevillano et al. e.p.). Actuaciones concretas y muy recientes han distorsionado notablemente el registro arqueológico de superficie (en algunos casos también las entidades arqueológicas que se encontraban en el subsuelo). La adaptación de las parcelas agrícolas a cultivos específicos (arroz, frutales...) ha requerido la total nivelación del terreno. Esto en ciertos casos ha destruido completamente todo rastro de evidencia material de prácticas agrarias en el pasado, aunque en la mayoría de espacios ha significado una alteración de la localización de los artefactos de mayor o menor importancia dentro de las áreas afectadas por las nivelaciones. De cualquier modo, este caso ejemplifica la desprotección de las entidades arqueológicas que no se amoldan al término yacimiento arqueológico tanto en la legislación sobre el patrimonio arqueológico nacional, como las regionales.

Al ejemplo citado se le pueden sumar experiencias similares de prospección superficial en áreas con elementos arqueológicos alterados por actuaciones recientes, como los tenemos en los trabajos realizados en La Mesa de Setefilla (Mesa et al. 1999), yacimiento ubicado en Lora del Río (Sevilla) y en La Veguilla (Gutiérrez et al. 2007), localizado en Úbeda (Jaén). En ambos trabajos, además de una caracterización cronológica y funcional de las distribuciones detectadas, se buscaba primordialmente evaluar el nivel de impacto y destrucción del registro arqueológico mediante técnicas de prospección microespacial en conjunción con sondeos en puntos seleccionados del área de estudio. Si bien en los dos casos las áreas de actividad concentrada merecen especial atención (la destrucción de estructuras se hace más evidente que la dislocación de fragmentos cerámicos en superficie), la totalidad del área prospectada 
es tratada con la misma intensidad tratando de integrar la mayor cantidad de elementos posibles dentro de un "registro arqueológico integral" (Gutiérrez et al. 2007: 784) que aglutina tanto elementos arqueológicos del subsuelo como de superficie a diversas escalas. Los resultados de ambos trabajos apuntan hacia la necesidad de llevar a cabo "verdaderas políticas de ARQUEOLOGÍA PREVENTIVA" (Mesa et al. 1999: 82) que optimicen los recursos y ayuden a proteger de forma efectiva el patrimonio arqueológico en consonancia con la idea por nosotros propuesta a mayor escala.

\section{Propuestas hacia el futuro. La necesidad de hibridación y ruptura de las barreras.}

Hasta aquí hemos reflexionado sobre el papel que estimamos le corresponde, en términos generales, a la prospección como fuente de conocimiento de primer orden para el estudio de los paisajes agrarios y para la protección de su legado. Pero no queríamos dejar de apuntar algunas otras consideraciones acerca de las líneas de evolución de los estudios territoriales que nos parecen estimulantes. Nos referimos a la potenciación de "espacios fronterizos", que implican la penetración de las formas de trabajar consideradas hasta aquí, en ámbitos en los que tradicionalmente no han tenido excesivo predicamento, al menos en nuestro entorno.

Diacronía es una bella palabra que con frecuencia adorna las declaraciones de intenciones en el momento de abordar esta clase de trabajos. Sin embargo a menudo este planteamiento biempensante no se corresponde con la realidad ni se cumple como objetivo. Bien es cierto que se trata de un propósito ambicioso, que fácilmente choca con las limitaciones materiales de numerosas iniciativas. Pero no es menos real que existe una poderosa inercia que potencia la perpetuación del viejo esquema académico de especialización en la problemática específica de períodos concretos.

A nadie se le escapa que la materialidad que la huella humana ha dejado en el paisaje en sus diversas facetas, es una realidad con límites difusos que no entiende de la segmentación marcada por las áreas de conocimiento tradicionales. Ya señalamos en la primera parte de este trabajo cómo para la arqueología medieval el estudio del paisaje es una especialidad plenamente consolidada y con sólidos antecedentes.

Sin embargo por su parte, la arqueología del mundo moderno y contemporáneo está mayoritariamente focalizada en el ámbito urbano, así como en el estudio de los procesos productivos y la actividad industrial. Cuando pensamos en la investigación sobre la historia agraria de dichas etapas, nos hallamos ante una fragmentación, que nos dirige en caminos paralelos hacia, por un lado, el análisis de la documentación escrita, y por otro hacia la evidencia material. Esta última tiende a su vez a compartimentarse en áreas de conocimiento muy especializadas, como el estudio de la morfología del paisaje, sobre todo de los sistemas y patrones de parcelación (González Villaescusa 1996, 2002), o la documentación y análisis de las construcciones rurales, a caballo entre la atención de etnógrafos, historiadores del arte y arquitectos. Los antropólogos han tendido a abandonar el estudio de esta arquitectura por considerarla un elemento ligado a sociedades ya desaparecidas, mientras que los arqueólogos a menudo la valoran como un elemento "periférico" en su registro. Por su parte, la evidencia arqueológica superficial permanece completamente disociada de los anteriores aspectos. Los mismos repertorios cerámicos que son objeto de atención en tanto que testimonios de actividades cotidianas, procesos de trabajo, intercambio, o expresión de la evolución de las artes decorativas, en el contexto de una indagación sobre las pautas de ocupación del territorio son comúnmente descartados como "ruido". 


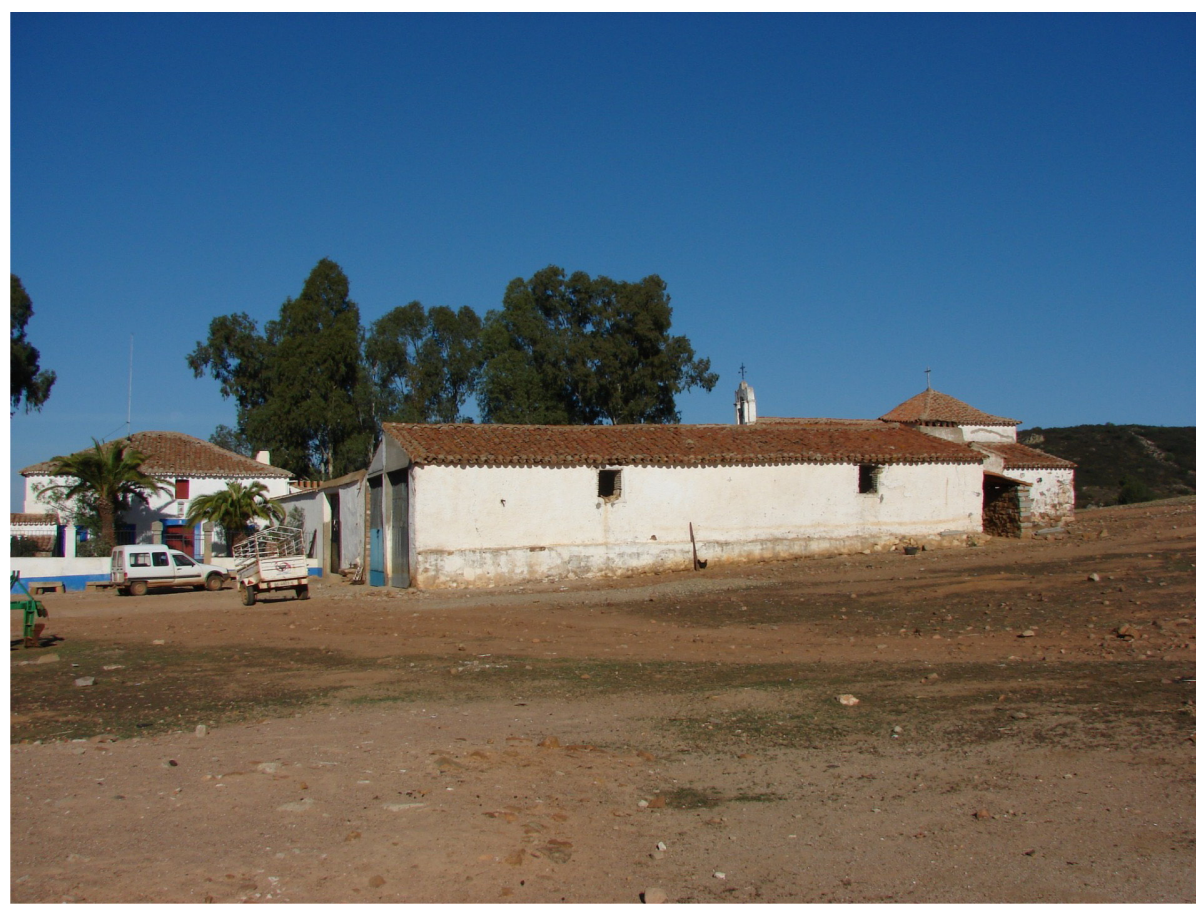

Figura 5. La arquitectura rural dispersa posee la misma profundidad temporal que el registro arqueológico superficial. Cortijo de la Ermita de San José (Quintana de la Serena, Badajoz).

Como quiera que los criterios de la prospección superficial raras veces contemplan, siquiera como posibilidad, un estudio de la evidencia "off site" de dichas etapas, no suele realizarse una recolección sistemática de estas evidencias. Y sin embargo suele tratarse de cerámicas cuya producción está muy bien documentada. Desde luego es el caso de muy diversos tipos de importaciones, pero se aplica igualmente a toda una "cacharrería popular" (Seseña 1997) de la que es posible incluso recuperar aún la memoria viva de las comunidades locales. Aun a riesgo de resultar utópicos en nuestro planteamiento, pensamos que existen buenas razones para afrontar el estudio de dichos materiales.

La principal es que fechando correctamente y delimitando esas presencias, obtenemos un testimonio directo sobre cómo ha evolucionado el uso del suelo en los espacios agrarios que estudiamos, un testimonio que no necesariamente ha de concordar con la imagen que se desprende del registro escrito. Comprender bien la entidad y naturaleza de estos cambios nos sirve a su vez como termómetro de la intensidad y el ritmo en la explotación de la tierra a través del tiempo.

Esta integración de la evidencia material del paisaje moderno y contemporáneo puede llevarnos un poco más allá, si consideramos el potencial de determinadas facetas de su historia más reciente. Como es bien sabido, en los últimos años ha cobrado un gran impulso el estudio arqueológico de los conflictos bélicos del siglo XX (Schofield 2005). En el caso peninsular esta temática se traduce obviamente en una revisión de contextos relacionados con nuestra Guerra Civil (1936-1939). Búnkeres y trincheras han sido objeto de documentación (Castellano Ruiz de la Torre 2004, 2008; González Ruibal 2008). Por su parte, el registro arqueológico de las trazas materiales de la represión tiene 


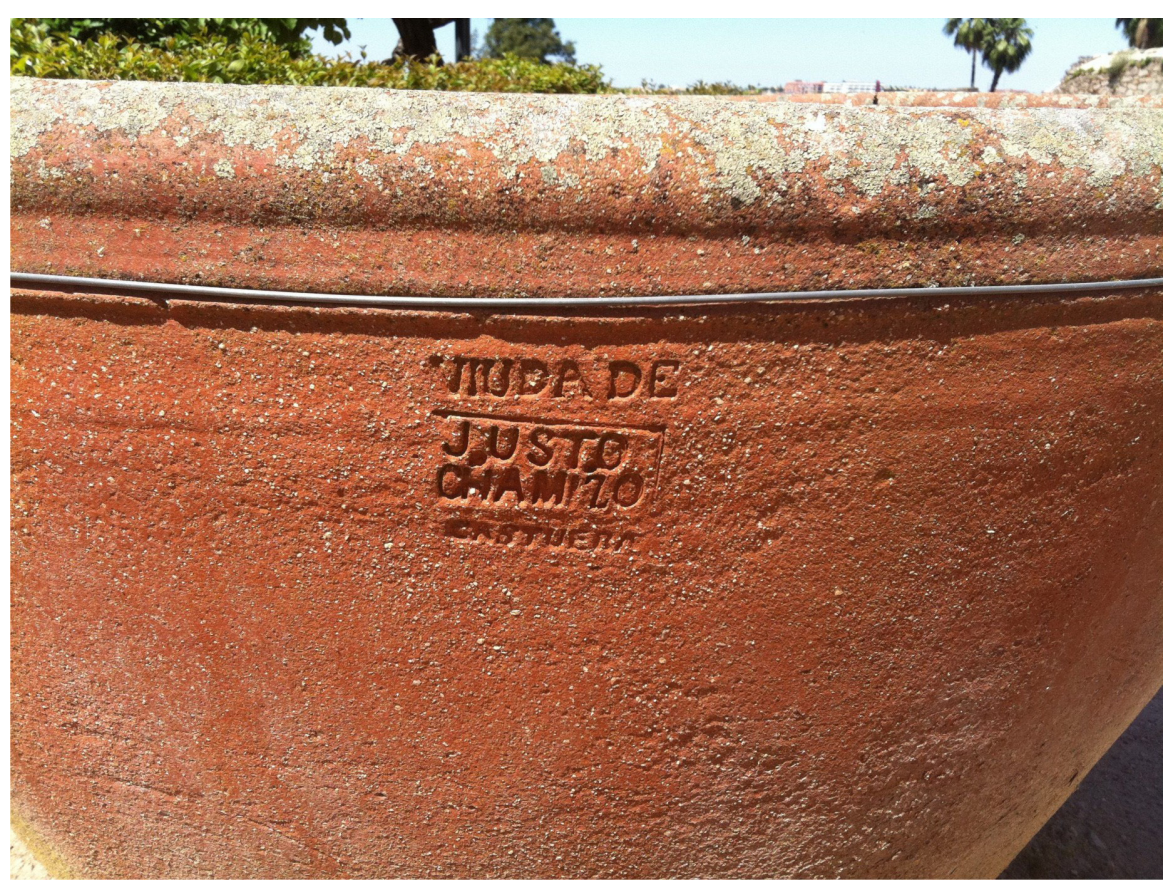

Figura 6. Un elocuente ejemplo de cómo las producciones de alfarería tradicional pueden ser cuidadosamente documentadas: gran contenedor producido en la Serena (Fotografía: Victorino Mayoral).

amplísimas implicaciones sociales y políticas. Así, se ha llevado a cabo un programa sistemático de excavación de numerosas fosas comunes por toda la geografía española (una valoración de conjunto puede consultarse en Gassiot 2008) y también pueden contarse algunas intervenciones en campos de concentración como el de Castuera (Badajoz) (González Ruibal 2011).

Sin embargo la memoria de estos acontecimientos tiene también como escenario los espacios agrarios. Es así como, una vez finalizada la contienda, un gran número de presos procedentes del bando perdedor fueron concentrados en las eufemísticamente llamadas "colonias penitenciarias", y empleados como trabajadores forzados para la construcción de infraestructuras para la puesta en regadío de amplios sectores de la vega del Guadiana (Gutiérrez Casalá 2003). El denominado "Plan Badajoz", que se desarrolló en los años posteriores, supuso una radical transformación de este paisaje aluvial fruto de las políticas del régimen franquista, y ha dejado igualmente un vasto legado material en forma de huertos, acequias, canales, granjas e instalaciones agrícolas. Esta colonización supuso además la fundación de gran número de poblaciones, cuya morfología y entidad empieza poco a poco a ser objeto de conservación y estudio (véase por ejemplo para Extremadura la obra de Espina Hidalgo y Cabecera Soriano 2010). A modo de ejemplo de actuaciones concretas, podríamos mencionar el caso de Vegaviana (Cáceres) en el valle del Alagón, reputado ejemplo de la arquitectura de este período y cuya declaración como Bien de Interés Cultural se ha promovido recientemente (Sánchez Expósito 2011). El mismo fenómeno se produjo en las demás cuencas hidrográficas peninsulares a través de la labor desarrollada por el Instituto Nacional de Colonización (Centellas Soler 2010). 

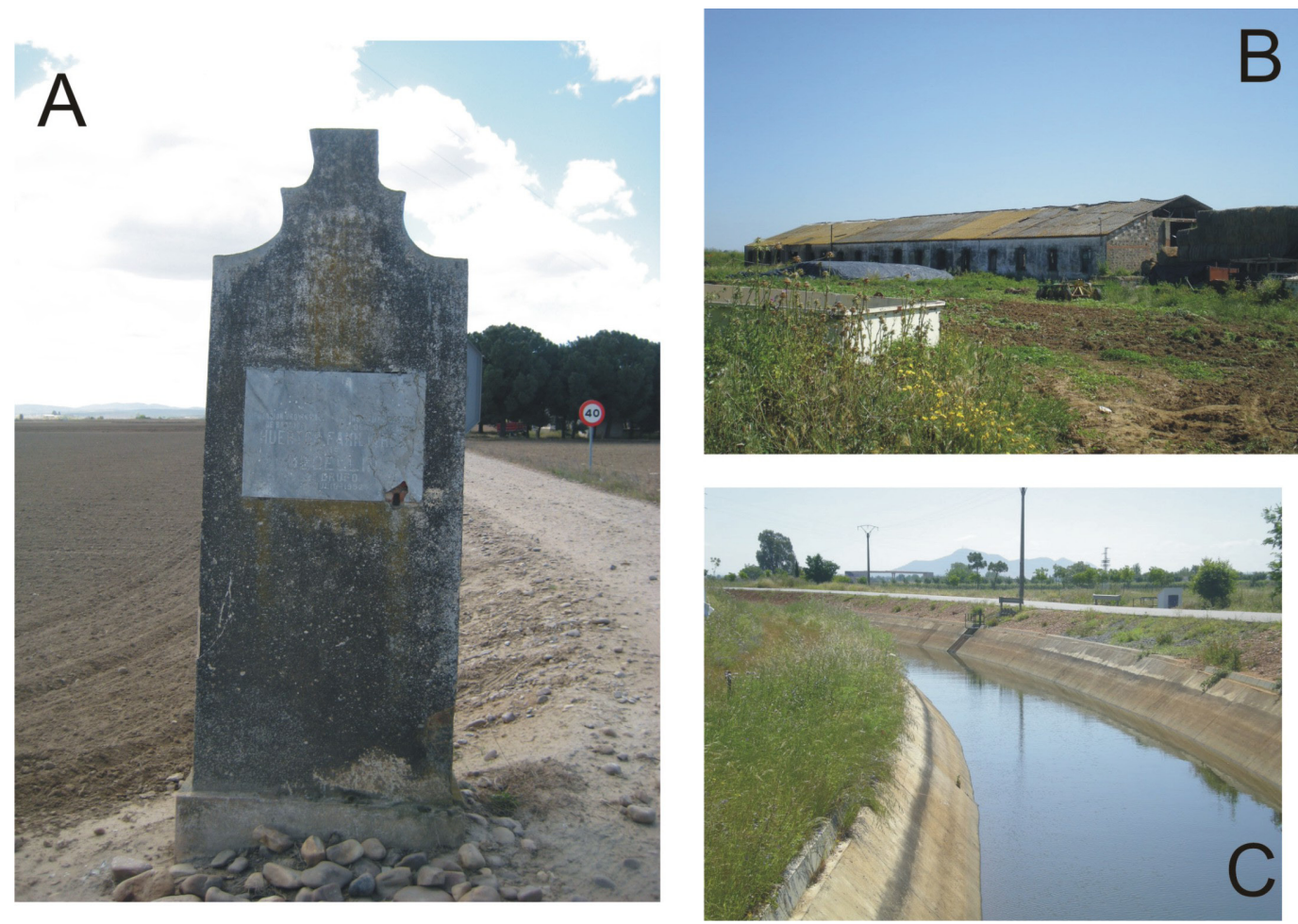

Figura 7. Evidencias de un paisaje agrario de la postguerra española. A.-Hito conmemorativo de la creación en 1952 de huertos familiares en Medellín (Badajoz). Fotografía: Victorino Mayoral. B-C.-La "colonia penitenciaria" de Montijo (Badajoz), y el canal construido por los presos concentrados en ella. Fotografía: José Manuel Corbacho Palacios (ARMHEX).

\section{Reflexiones finales}

Aunque puede decirse que los estudios arqueológicos sobre el paisaje gozan de buena salud en el ámbito peninsular, en este trabajo hemos querido llamar la atención sobre la necesidad de no perder de vista el "gran cuadro" en el que encuentra su lugar una caleidoscópica multiplicidad de aportaciones. Desde nuestro punto de vista, este planteamiento permite levantar sólidos puentes entre el quehacer diario o la complejidad tecnológica de los métodos, y la plenitud de sentido de nuestra disciplina en tanto que ciencia social.

Un concepto central en ese vínculo entre método y teoría es el de la importancia de una renovación permanente por lo que respecta a la prospección arqueológica superficial. A este respecto cabe señalar que sigue siendo necesario traspasar las fronteras del sitio como categoría básica de análisis, así como la formalización de sistemas de registro orientados a la documentación de la evidencia off-site con toda su complejidad. Al mismo tiempo, seguimos necesitados de un cuerpo de evidencia experimental para la contrastación de un buen número de las asunciones previas formuladas en relación con la representatividad de los materiales superficiales. Mantener viva la discusión que permita el avance en lo relativo a estas cuestiones no debería por más tiempo depender mayoritariamente de la consulta de una literatura científica externa. Sería en cambio muy positivo potenciar la puesta en común a través de encuentros periódicos, que crearan un foro informal y abierto volcado 
en la discusión, lejos del aparato y la rigidez de los congresos al uso. La experiencia de los International Mediterranean Survey Workshops, que se vienen celebrando desde el año 2000 en el ámbito de los Países Bajos, puede considerarse inspiradora en este sentido.

Agradecimientos: Queremos expresar nuestro agradecimiento en primer lugar a Dña. Patricia Murrieta Flores por la amable invitación para participar en el presente volumen. Gracias además a D. José Manuel Corbacho Palacios, presidente de la Asociación para la Recuperación de la Memoria Histórica de Extremadura, por su desinteresada colaboración autorizando la reproducción de las fotografías del Canal y la Colonia Penitenciaria de Montijo. Gracias igualmente a Maribel Martínez Navarrete, Teresa Chapa y Trinidad Tortosa por sus amables comentarios y sugerencias para la elaboración de este trabajo.

\section{Bibliografía citada}

Alcock, S. y J.F. Cherry (eds.)

2004 Side-by-Side Survey. Comparative Regional Studies in the Mediterranean World. Oxbow, Oxford.

Alcock, S., Cherry, J.F. y J.L. Davis

1994 Intensive survey, agricultural practice and the classical landscape of Greece. Classical Greece: Ancient Histories and Modern Archaeologies (ed. I. Morris), pp. 137-170. Cambridge University Press, Cambridge.

Almagro Gorbea, M. y J.E. Benito López

1993 La prospección arqueológica del valle del Tajuña. Una experiencia teórico-práctica de estudio territorial en la Meseta. Complutum 4: 297-310.

Ammerman, A.J.

1985 PLow-Zone Experiments in Calabria, Italy. Journal of Field Archaeology 12 (1): 33-40.

Banning, E.B.

2002 Archaeological Survey. Kluwer Academic/ Plenum Publishers, Nueva York.

Barceló, M.

1988. La arqueología extensiva y el estudio de la creación del espacio rural. Crítica, Barcelona.

Barker, G.

1995. A Mediterranean valley: Landscape Archaeology and Annales history in the Biferno valley. Leicester University Press, Londres.

Bazzana, A. y A. Humbert

1983 Prospections aériennes. Les paysages et leur histoire. Casa de Velázquez, Série Recherches en Sciences Sociales 7, Madrid.

Benito López, J.E.

2004 Los factores no controlables por el arqueólogo como parámetros de análisis en los proyectos de prospección arqueológica. Una expereincia teórico-práctica en la Meseta (El Valle del Tajuña, Madrid). Arqueología Espacial 24-25: 251-258. 
Bintliff, J.L., Howard, P. y A. Snodgrass

1999 The Hidden Landscape of Prehistoric Greece. Journal of Mediterranean Archaeology 12(2): 139-168.

Bintliff, J.L. y A. Snodgrass

1988 Off-Site Pottery distributions: A Regional and Interregional Perspective Current Antropology 29(3): 506-513.

Burillo Mozota, F.

1996 Prospección arqueológica y geoarqueología. Arqueología Espacial 15: 67-82.

2004 Arqueología Espacial: Prospección. Arqueología Espacial, Teruel.

2010 Arqueología de la Población. Arqueología Espacial 28. Seminario de Arqueología y Etnología Turolense. Colegio Universitario de Teruel, Teruel.

Burillo Mozota, F. y J.L. Peña Monné

1984 Modificaciones por factores geomorfológicos en el tamaño y ubicación de los asentamientos primitivos. Arqueología Espacial 1: 91-106.

Burillo Mozota, F., Ibáñez González, E.J. y E. Alegre Aparicio

2004 Prospección y concepto de asentamiento. El caso de la ciudad celtibérica de Segeda I. Arqueología Espacial 24-25: 165-184.

Burillo Mozota, F., Ibáñez González, E.J. y C. Polo Cuntando

1993 Ficha General de la Carta Arqueológica de Aragón I: Localización y descripción física del yacimiento y su entorno.

Carandini, A.

1997 Historias de la tierra. Manual de excavación arqueológica. Crítica, Barcelona.

Carretè, J.M., Keay, S.J. y M. Millet

1995 A Roman Provincial Capital and its Hinterland. The Survey of the Territory of Tarragona, Spain 1985-1990. JRA Supplementary Series, Michigan.

Castellano Ruiz de la Torre, R.

2004. Los restos del asedio. Fortificaciones de la Guerra Civil en el frente de Madrid. Ejército Nacional. Almena, Madrid.

2008 La recuperación de vestigios arqueológicos de la Guerra Civil Española. Experiencia y método: el caso de Guadalajara. Complutum 19: 33-46.

Centellas Soler, M.

2010 Los pueblos de colonización de la administración franquista en la España rural. $P+C$ : proyecto y ciudad: revista de temas de arquitectura 1: 109-126.

Chapa, T., Uriarte, A., Vicent, J.M., Mayoral, V. y J. Pereira

2003 Propuesta metodológica para una prospección arqueológica sistemática: el caso del Guadiana Menor (Jaén, España). Trabajos de Prehistoria 60 (1): 11-34. 
Cherry, J.F.

1991 Landscape archaeology as long-term history: Northern Keos in the Cycladic Islands from earliest settlement until modern times. Monumenta Archaeologica 16, Universidad de California, Los Angeles.

Conolly, J. y M. Lake

2006 Geographical Information Systems in Archaeology. Cambridge Manuals in Archaeology. Cambridge Universitiy Press, Cambridge.

Cressier, P.

1983 L’Alpujarra medievale: une approche archeológique. Melánges de la Casa de Velázquez 19-1: 89-125.

Criado Boado, F.

1993 Límites y posibilidades de la Arqueología del Paisaje. Spal 2: 9-56.

1999. Del terreno al espacio: planteamientos y perspectivas para la Arqueología del Paisaje. CAPA 6: 1-82.

Díaz Iglesias, J. M., Rodrigo Cámara, J. M. y S. Fernández Cacho 2011 Sistema de cartografía arqueológica predictiva. PRONOS. Revista Instituto Andaluz de Patrimonio Histórico 77: 107-109.

Díez Martín, F.

1999 Observaciones sobre la incidencia del laboreo agrícola en los agregados líticos. El experimento de Las Cuestas (Tudela de Duero, Valladolid). BSAA Arqueología 65: 29-42.

2009. La arqueología de los espacios arados. Algunas puntualizaciones. BSAA Arqueología 75: $23-40$

Dunnell, R.C. y W.S. Dancey

1983 The siteless survey: A regional scale data collection strategy. Advances in Archaeological Method and Theory 6: 267-285.

Dunnell, R.C. y J.F. Simek

1995 Artifact size and Plowzone Processes. Journal of Field Archaeology 22(3): 305-319.

Espina Hidalgo, S. y R. Cabecera Soriano (coords.)

2010 Los pueblos de colonización en Extremadura. Junta de Extremadura, Badajoz.

Esteban, A., Sánchez, A., Risquez Cuenca, C. y M. Molinos Molinos

1996 Hechos deposicionales y postdeposicionales. Aspectos metodológicos para la definición de la "coyuntura cero". Arqueología Espacial 16-17: 279-296.

Fanning, P.C. y S.J. Holdaway

2004 Artifact Visibility at Open Sites in Western New South Wales, Australia. Journal of Field Archaeology 29 (3-4): 255-271.

Fernández Cacho, S. y J.M. Rodrigo Cámara (coord.)

2009 MAPA: Modelo Andaluz de Predicción Arqueológica. E-ph Cuadernos, http:/ / www. juntadeandalucia.es/cultura/iaph/nav/modeloandaluzdeprediccionarqueologica. 
Fernández Martínez, V.M.

1985 Las técnicas de muestro en prospección arqueológica. Revista de Investigación del Colegio Universitario de Soria 9: 7-47.

García Sánchez, J.

2012 Neo-procesualismo como una renovación crítica, un ejemplo desde el paisaje. ArkeoGazte 2: 95-112.

Gassiot Ballbè, E.

2008 Arqueología de un silencio: arqueología forense de la Guerra Civil y del franquismo. Complutum 19(2): 119-130.

Gillings, $\mathrm{M}$.

2000 The utility of the GIS approach in the collection, management, storage and analysis of surface survey data. The Future of Surface artifact Survey in Europe (ed. por J. Bintliff, M. Kuna y N. Venclova), pp. 105-120. Sheffield Academic Press, Sheffield

Given, M.

2004 Mapping and manuring: can we compare sherd density figures? Side-by-Side Survey. Comparative Regional Studies in the Mediterranean World (ed. S. Alcock y J.F. Cherry), pp. 1321. Oxbow, Oxford.

González Ruibal, A.

2008 Arqueología de la Guerra Civil Española. Complutum 19: 11-20.

2011 Excavaciones arqueológicas en el campo de la concentración de Castuera (Badajoz): primeros resultados. Revista de Estudios Extremeños 67(2): 701-749.

González Villaescusa, R.

1996 Paisaje agrario, regadío y parcelarios en la Huerta de Valencia. Nuevos planteamientos desde el análisis morfológico. II Coloquio Historia y Medio Físico, pp. 343-360. Instituto de Estudios Almerienses, Almería.

2002 Las formas de los paisajes mediterráneos. Universidad de Jaén, Jaén.

Grau Mira, I. (ed.)

2006 La aplicación de los SIG en la arqueología del paisaje. Servicio de Publicaciones de la Universidad de Alicante, Alicante.

Guichard, P.

1987 Estudios sobre historia medieval. Alfons el Magnànim, Valencia.

Guilaine, J.

1991. Pour une Archéologie Agraire. Armand Colin, Paris.

Gutiérrez Casalá, J. L.

2003. Colonias penitenciarias militarizadas de Montijo: represión franquista en el partido judicial de Mérida. Editora Regional de Extremadura, Mérida.

Gutiérrez Soler, L. M.

2010 Microprospección arqueológica en Giribaile (Vilches, Jaén). Protocolo de trabajo. Trabajos de Prehistoria 67(1): 7-35. 
Gutiérrez Soler, L. M., Bellón Ruíz, J. P. y B. Ceprián del Castillo

2007 La Veguilla (Úbeda, Jaén). Prospección de superficie y caracterización del registro arqueológico. Caesaaugusta 78: 781-792.

Gutiérrez Soler, L.M., Royo, M.A., Bellón, J.P. y V. Barba 1998 Microprospección de superficie en el entorno del monumento. El santuario heróico de "El pajarillo", Huelma (Jaén) (ed. por M.C. Molinos, A. Ruíz, J. Pereira, C. Rísquez, A. Madrigal, A. Esteban, V. Mayoral y M. Llorens. Servicio de Publicaciones de la Universidad de Jaén, Jaén.

Harris, E.

1991 Principios de estratigrafía arqueológica. Crítica, Barcelona.

Hurtado Pérez, V.

2000 Surface survey annalysis of the copper age site of La Pijotilla. The Archaeology of Mediterranean Landscapes 5. Extracting Meaning fron Ploughsoil Assemblages (ed. por G. Barker, R. Francovich y H. Patterson). Oxbow Books, Oxford.

Keay, S., Carreté, J.M. y M. Millet

1989 Ciutat i camp en el mòn romà: Les prospeccions a l'Ager Tarraconensis Tribuna d' Arqueología 1988-1989: 121-129.

Keay, S., Creighton, J. y J. Remesal Rodriguez (eds).

2001 Celti (Peñaflor). La arqueología de una ciudad hispanorromana en la Baetica: prospecciones y excavaciones 1987-1992. Arqueología Monografías. Conserjería de Cultura, Sevilla.

Kirchner, H. (ed)

2010 Por una arqueología agraria. Perspectivas de investigación sobre espacios de cultivo en las sociedades medievales hispánicas. BAR International Series 2062, Oxford.

Ladrón de Guevara Sánchez, M.C. y V. Muñoz Cruz (coord.)

2007 El Sistema de Información del Patrimonio Histórico de Andalucía (SIPHA). Cuadernos PH 20. Junta de Andalucía, Consejería de Cultura, Instituto Andaluz del Patrimonio Histórico, Sevilla.

Lorrio Alvarado, A.J. y V.M. Fernández Martínez

1986 Relaciones entre datos de superficie y del subsuelo en yacimientos arqueológicos. Un caso práctico. Arqueología Espacial 7: 183-198.

Martín Bravo, A.M.

1994 Metodología de prospección para la Edad del Hierro en la zona de Alcántara. Zephyrus 46: 183-194.

1996. Las sociedades de la edad del hierro en la Alta Extremadura. Departamento de Prehistoria, Facultad de Geografía e Historia, Universidad Complutense, Madrid.

Martín Bravo, A.M., Benito López, J.E. y M. Almagro Gorbea

1996 Control de calidad de resultados en prospección arqueológica. Complutum 7: 251-264.

Martínez Navarrete, M.I.

1997-98. The development of Spanish archaeology in the 20th century. Archaeologia Polona 35-36: 319-342. 
Mayoral Herrera, V. y S. Celestino Pérez (eds)

2011 Tecnologías de información geográfica y análisis arqueológico del territorio. Actas del $V$ Simposio Internacional de Arqueología de Mérida. Anejos de AESPA. Instituto de Arqueología de Mérida. CSIC. Junta de Extremadura. Consorcio de Mérida, Mérida.

Mayoral Herrera, V., Cerrillo Cuenca, E. y S. Celestino Pérez

2009 Métodos de prospección arqueológica intensiva en el marco de un proyecto regional: el caso de la comarca de La Serena (Badajoz). Trabajos de Prehistoria 66(1): 7-25.

Mayoral, V., Uriarte, A., Chapa, T., Vicent, J. y A. Cabrera

2011 'Background noise' and landscape exploitation in the Late Iron Age Andalusian countryside. Hidden Landscapes of Mediterranean Europe. Cultural and methodological biases in pre- and protohistoric landscape studies (ed. por M.V. Leusen, G. Pizziolo y L. Sarti), pp 265-270. Collegio S. Chiara, University of Siena. BAR International Series, Archeopress.

Mayoral, V., Borja Barrera, F., Borja Barrera, C., Martínez Del Pozo, J.A. y M. De Tena 2011 The evolution of an agrarian landscape. Methodological proposals for the archaeological study of the alluvial plain of Medellin (Guadiana basin, Spain). Landscape Archaeology between Art and Science - From a multi- to an interdisciplinary approach (ed. por S.J. Kluiving y E.B. Guttmann-Bond), pp. 97-114. Landscape \& Heritage Series, Proceedings, Amsterdam University Press, Amsterdam.

Mesa, M., De la Ascensión Salas, J. y J. Sánchez

1999 Análisis Microespacial y Arqueología de Gestión: Una experiencia en el yacimiento de La Mesa de Setefilla (Lora del Río, Sevilla). Arqueología Espacial 21: 65-83.

Miller, N. y K. Gleason

1998 The archaeology of garden and fields. University of Pensylvania Press, Philadelphia.

Orejas Saco del Valle, A.

2006 Arqueología de los paisajes agrarios e historia rural. Arqueología Espacial 26: 7-20.

Parcero Oubiña, C.

2006 Los paisajes agrarios castreños. Modelos de construcción del espacio agrario a lo largo de la Edad del Hierro del noroeste. Arqueología Espacial 26: 57-85.

Pasquinucci, M. y S. Menchelli

2012 Surveying the Complexity: A Global Approach to Italian Landscapes. eTopoi, Journal for Ancient Studies. Special Volume 3: 101-105.

Quesada Sanz, F. y D. Vaquerizo Gil

1990 Un proyecto de investigación arqueológica en Córdoba: “Protohistoria y Romanización en la subbética cordobesa". Anales de Arqueología Cordobesa 1: 7-52.

Rodríguez Díaz, A.

2009 Campesinos y "señores del campo". Tierra y poder en la protohistoria extremeña. Bellaterra, Barcelona. 
Ruiz del Árbol, M.

2005. La Arqueología de los espacios cultivados. Terrazas y explotación agraria romana en un área de montaña: La Sierra de Francia (Salamanca). Consejo Superior de Investigaciones Cientificas, Madrid.

2006 Los paisajes agrarios del NE de Lusitania: terrazas y explotación agraria romanas en la Sierra de Francia. Arqueología Espacial 26: 115-142.

Ruiz Rodríguez, A.

1988 Reflexiones sobre algunos conceptos de la arqueología espacial a partir de una experiencia: Iberos en el Alto Guadalquivir. Arqueología Espacial 12: 157-172.

Ruíz Rodríguez, A. y M. Molinos

1979 Algunas consideraciones para la reconstrucción de las relaciones sociales en los sectores dominantes de la producción económica ibérica (agricultura y minería). Memorias de Historia Antigua 3: 147-155.

1984. Elementos para un estudio del patrón de asentamiento en las campiñas del Alto Guadalquivir durante el Horizonte Pleno Ibérico (un caso de sociedad agrícola con Estado). Arqueología Espacial 4: 187-206.

Ruiz Rodríguez, A., Risquez Cuenca, C. y M. Molinos Molinos

1998 Paisaje y territorio mundo: dos dimensiones de una misma teoría arqueológica. Arqueología Espacial 19: 21-32.

Ruiz Rodríguez, A., Serrano Peña, J.L., Molinos Molinos, M. y M.O. Rodríguez Ariza 2007 La tierra y los iberos en el Alto Guadalquivir. Arqueología de la tierra. VI Cursos de Verano Internacionales de la Universidad de Extremadura (ed. A. Rodríguez Díaz e I. Pavón Soldevilla). Universidad de Extremadura, Cáceres.

Ruíz Zapatero, G.

2004 La prospección arqueológica en los inicios del siglo XXI. Arqueología Espacial 24-25: 17-32.

Ruíz Zapatero, G. y F. Burillo Mozota

1988 Metodología para la investigación en arqueología territorial. Munibe 6: 45-64.

Ruiz Zapatero, G. y V. Fernández Martínez

1993 Prospección de superficie, técnicas de muestreo y recogida de la información Actas, Inventarios y Cartas arqueológicas (Homenaje a Blas Taracena). Junta de Castilla y León, Soria.

San Miguel Mate, L.C.

1992 El planteamiento y el análisis del desarrollo de la prospección: dos capítulos olvidados en los trabajos de arqueología territorial. Trabajos de Prehistoria 49: 35-49.

Sánchez, I.

2011 Vegaviana (España), la experiencia de la colonización y la creación de una identidad social. Revista de Estudios Etnográficos de la Asociación Profesional Extremeña de Antropología 2: 131-148.

Schofield, J.

2005 Combat archaeology. Material culture and modern conflict. Duckworth, Londres. 
Seseña, N.

1997 Cacharrería popular: la cerámica de basto en España. Alianza, Madrid.

Sevillano Perea, L., Mayoral Herrera, V., Salas Tovar, E., Liceras Garrido, R. y F.J. Heras Mora (e.p.). Detectando prácticas agrarias antiguas en el territorio sur de Medellín. La expresión material de las actividades agrarias protohistóricas del suroeste peninsular. VI Jornadas de Arqueología del Suroeste Peninsular. Villafranca de los Barros, 4-6 de octubre de 2012. Ayuntamiento de Villafranca de los Barros, Gobierno de Extremadura, Universidad de Huelva.

Shennan, S.

1985 Experiments in the Collection and Analysis of Archaeological Surface Data: The East Hampshire Survey. Sheffield University Press, Sheffield.

Shott, M.J.

1995 Reliability of Archaeological Records on Cultivated Surfaces: A Michigan Case Study. Journal of Field Archaeology 22(4): 475-490.

Vicent, J.M.

1991 Fundamentos teórico-metodológicos para un programa de investigación arqueogeográfica. El cambio cultural del IV al II milenios a.C. en la comarca noroeste de Murcia (ed. por P. López), vol.1., pp. 29-102. Consejo Superior de Investigaciones Cientificas, Madrid.

Wandsnider, L. y E. Camilli

1992 The Character of surface archaeological deposits and its influence on survey accuracy. Journal of Field Archaeology 19: 169-187.

Wheatley, D. y M. Gillings

2002 Spatial technology and archaeology: a guide to the archaeololgical applications of GIS. Taylor \& Francis, London.

Wilkinson, T. J.

1982 The Definition of Ancient Manured Zones by Means of Extensive Sherd-sampling Techniques. Journal of Field Archaeology 9: 323-333.

1989 Extensive sherd scatters and land-use intensity: some recent results . Journal of Field Archaeology 16: 31-46.

1992 Off-site archaeology. National Geographic Research and Exploration 8: 196-207.

2000 Regional Approaches to Mesopotamian Archaeology: The Contribution of Archaeological Surveys. Journal of Archaeological Research 8(3): 219-267. 